\title{
Propuesta del modelo para control de infecciones en la consulta odontológica ante la pandemia de COVID-19.
}

\author{
Proposal for an infection control protocol in the dental \\ consultation against the COVID-19 pandemic.
}

Laura María Díaz Guzmán,* José L Castellanos Suárez

\section{RESUMEN}

Catalogada su labor como Servicios de Salud Indispensables, el profesional de la odontología se ha mantenido al pendiente de sus pacientes durante la pandemia de COVID-19, brindando atención de urgencia a quien lo solicita. A su regreso a la práctica típica, el odontólogo encontrará un entorno distinto o NUEVA NORMALIDAD, viéndose obligado a hacer modificaciones clínicas pertinentes y preparar a su equipo de trabajo para continuar brindando atención de calidad con un margen de seguridad amplificado, que de igual manera proteja a pacientes y al equipo de trabajo. Ante la falta de una vacuna que brinde protección y de tratamiento específico contra el SARS-CoV-2 (COVID-19), elevar el nivel de control de infecciones en el consultorio se vuelve ineludible y posiblemente irreversible en el quehacer odontológico cotidiano. En este artículo se propone un Protocolo de Control de Infecciones en la consulta odontológica que permita brindar seguridad en la atención bucal, considerando COVID-19, útil también para control infeccioso de otros patógenos virales o bacterianos.

Palabras clave: COVID-19, control de infecciones, bioseguridad, atención odontológica.

\section{ABSTRACT}

Considered dentistry as an Indispensable Health Services, during the COVID-19 pandemic the dental professional has been providing mostly emergency care. Upon return to typical dental practice, the dentist will find a different environment or NEW NORMALLY, being forced to make relevant clinical modifications and prepare his team to continue providing quality care with an amplified safety margin, which equally protects patients and dental team. In the absence of an available vaccine that provides protection or a specific treatment against SARSCoV-2 (COVID-19), raising the level of infection control at the dental office will become unavoidable and possibly irreversible in the future quotidian dental work. This article proposes an Infection Control Protocol for the dental consultation that allows provide safety oral care, considering COVID-19, also useful for other viral or bacterial pathogens control.

Keywords: COVID-19, infection control, biosecurity, dental care.

\section{INTRODUCCIÓN}

$\mathrm{H}$ an existido eventos en la historia de la humanidad que modificaron los estilos de vida para siempre, algunos tan impactantes que obligaron a cambios ostensibles en el mejoramiento en su calidad de vida. En las ciencias médicas existen muchos ejemplos de estos puntos de quiebre,

* Práctica privada de la Odontología.

‡ Práctica Limitada a Medicina Bucal y Periodoncia

KD Digital. Centro de Apoyo Diagnóstico. Socio. León, Guanajuato. México.

Recibido: 31 Mayo 2020.

Aceptado para publicación: 07 Junio 2020. como son el descubrimiento de los microorganismos, de la penicilina, las vacunas o el trasplante de órganos.

En los años 80 la epidemia del VIH-SIDA generó toda una modificación en los procesos de trabajo de la medicina, de lo cual la odontología no quedó excluida. De trabajar con un buen nivel de limpieza e higiene, se dio un giro muy importante, ya que dio paso a los procesos de control de infecciones y bioseguridad que se practican en la actualidad en los consultorios y clínicas odontológicas del mundo. Este es el caso de la pandemia generada por el SARS-CoV-2, un virus cuya rápida expansión ha colapsado sistemas de salud en el mundo, aun en los países desarrollados, que ha generado la determinación de las autoridades sanitarias de hacer imprescindible el confinamiento de las personas 
en sitios seguros, ha puesto en riesgo la estabilidad económica mundial y ha obligado a tomar medidas sanitarias y psicosociales para proteger la vida y la condición humana en múltiples regiones del orbe. ${ }^{1-4}$

Fue el último día del año 2019 que las autoridades sanitarias chinas advirtieron a la comunidad científica mundial haber manejado en la ciudad de Wuhan, China, entre el $1^{\circ}$ de diciembre de 2019 y el 2 de enero de 2020 un brote de neumonía de origen desconocido en 41 pacientes. Para el 7 enero de 2020 ya estaba disponible a la comunidad científica mundial la información sobre un nuevo coronavirus causante de neumonía y fibrosis pulmonar, al que la Organización Mundial de la Salud (OMS) denominó 2019 novel coronavirus (nCoV-2019). Para el 10 de enero de 2020 China reportó la primera muerte por la enfermedad ya denominada COVID-19. A partir de entonces empezó la rápida diseminación de esta pandemia, siendo Tailandia el primer país afectado fuera de China; después siguieron Japón y Corea y de ahí al resto del mundo. ${ }^{2}$ Con más de 6 millones de casos confirmados a la fecha a nivel mundial y casi 400,000 decesos, esta enfermedad ha modificado, sin duda para siempre, las tradicionales medidas de protección al no haberse descubierto aún un medicamento antiviral eficaz, ni desarrollado hasta el momento una probada vacuna que proteja a la población.

Catalogada como servicio indispensable de salud, la atención odontológica se ha mantenido vigente en su quehacer en medio del confinamiento mundial, dedicándose inicialmente al manejo de las urgencias odontológicas y pendientes de la salud oral de los pacientes por vía telefónica y mensajería electrónica. ${ }^{5-12}$

Con el reinicio de las actividades laborales y económicas y en un entorno llamado NUEVA NORMALIDAD, en la que como ya fue expresado, aún no existe vacuna ni tratamiento farmacológico específico, el odontólogo debe estar preparado para dar a los pacientes y al personal (clínico, administrativo, de laboratorio y otros) seguridad antiinfecciosa contra SARS-CoV-2. Acciones que deben ser adecuadamente comunicadas, entendidas y ejecutadas, ponderando el beneficio directo como familiar y hacia la sociedad. ${ }^{10-13}$

La pandemia de COVID-19 induce a cavilar respecto a la posibilidad de enfrentar nuevas pandemias y al hecho de la conveniencia y pertinencia de elevar el nivel del control de infecciones en odontología, haciendo ajustes y mejoras de manera permanente como parte de una estrategia de atención con seguridad antiinfecciosa para todos los involucrados, tanto usuarios como prestadores directos e indirectos de los servicios odontológicos. ${ }^{13,14}$
A continuación se presenta un modelo de control de infecciones suplementario a aquel que todos los odontólogos han implementado desde tiempo atrás en sus consultorios. Al saber que las especialidades odontológicas tienen diferentes niveles de riesgo de contagio y de posibilidades de generar infección cruzada, este modelo se puede adaptar o hacer modificaciones a sus propias necesidades bajo los protocolos sugeridos.

En la preparación de la clínica para regresar a la Ilamada «NUEVA NORMALIDAD» deben contemplarse diversos aspectos que serán tocados a continuación. Esta propuesta está establecida en un protocolo que incluye una serie de procesos que tienen como objetivo mantener la calidad de la atención odontológica con seguridad para el bienestar de los solicitantes de atención dental, así como la propia seguridad de aquéllos que forman parte del equipo de trabajo y, aún más, para los colaboradores externos y la familia.

\section{PROTOCOLO DE CONTROL DE INFECCIONES EN LACONSULTA ODONTOLÓGICADURANTE Y DESPUÉS DE LA PANDEMIA DE COVID-191,5-12,15-20}

\section{A. Informando a los pacientes de la reapertura de los servicios odontológicos}

Hay diferentes maneras de hacer saber a los pacientes que se está de regreso. Se les puede informar por vía telefónica, correo electrónico, por aplicaciones telefónicas de comunicación, como WhatsApp, Facebook, Instagram o redes similares, las cuales juegan un papel muy importante en la comunicación y deben ser aprovechadas anunciando los niveles incrementados de control infeccioso para seguridad de los pacientes que van a recibir tratamiento odontológico.

\section{B. Preparación de instalaciones, equipo y personal para volver a la NUEVA NORMALIDAD}

\section{Instalaciones y equipo}

Para el regreso al completo funcionamiento de la clínica o consultorio después de semanas de confinamiento de la mayoría de los pacientes, debe haber algunas adecuaciones orientadas a cubrir varios objetivos: a) mejorar la experiencia del paciente, b) hacer altamente eficientes los procesos de operación, c) incremento en el nivel de control de infecciones. Pudiera ser necesario modificar la circulación de personas (pacientes y personal clínico), modificar la posición física de las zonas 
de trabajo y generar espacio para guardar la adecuada distancia (1.5-2 m). Entre los elementos que deben incluirse al preparar las instalaciones están:

- Tapete humedecido. Se colocará en la entrada. Humedecido en una solución de hipoclorito de sodio al $1.5 \%$ para que las personas que ingresen se limpien los zapatos.

- Gel antibacterial. Se colocará un dispensador de éste en la entrada y a la vista de los pacientes. Deberá ser usado por quienes ingresen a la clínica. Pueden colocarse dispensadores adicionales a conveniencia.

- Carteles educativos. Para visitantes y personal clínico. Se colocarán de manera visible en todas las áreas físicas, incluyendo el laboratorio. Algunos pueden ser descargados desde las plataformas de la Secretaría de Salud del Gobierno de la República, de la Organización Mundial de la Salud (OMS), de la Federación Dental Internacional (FDI), la Asociación Dental Americana (ADA), entre otras instituciones mundialmente reconocidas. Los mensajes pueden ser variados, ajustados a la información conveniente que se desea transmitir y al área de trabajo, que permitan informar aspectos como:

- Que se ha elevado el nivel del Protocolo de Control de Infecciones de la clínica, ajustado a las exigencias impuestas por la contingencia del COVID-19.

- Sana distancia. Indicar y exigir su observancia.

- Proscribir el uso de teléfonos móviles en cualquiera de las instalaciones de la clínica. Éste es un artefacto altamente contaminado y contaminante.

- Invitar a toda persona que ingrese a las instalaciones a usar el gel antibacterial.

- Mostrar la técnica correcta del lavado de manos.

- Bloqueo de las secreciones que se producen al estornudar o toser con el pliegue del antebrazo.

- Mamparas y barreras físicas. Se colocará una mampara de acrílico en el mostrador de la recepción para limitar el contacto del personal de recepción con usuarios y visitantes, que permita el intercambio de documentos, dinero o la terminal bancaria. Otra manera de guardar distancia es marcando en el piso una línea que no debe ser rebasada por el paciente o acompañantes al acercarse al mobiliario del área de recepción. El uso de caretas es una alternativa.

- Bloqueo o disminución de asientos. Se bloquearán asientos en la sala de espera o se separarán más de $1.5 \mathrm{~m}$ sillones o sillas individuales (sana distancia).
Inclusive pudiera ser necesario reducir el número de asientos disponibles en la sala de espera.

- Preparación del mobiliario e instalaciones. Todos los días el personal, previo protocolo de lavado de manos, antebrazos y cara, protegido con guantes de nitrilo, hará la limpieza de las instalaciones. En cada turno y entre cada paciente el personal limpiará con hipoclorito de sodio (30 mL de cloro en 1 litro de agua) las superficies de trabajo y de contacto de personal y pacientes (manijas, mostrador, botones, etcétera) y colocará barreras de protección en todas las superficies de los equipos, charolas de instrumental y en aquéllas que puedan ser tocadas, tales como teclados, receptores telefónicos, botones, picaportes, manijas, descansabrazos, entre otros.

- Eliminación de objetos contaminantes. Por ser de potencial contaminante alto y de difícil control sanitario, deben ser retiradas revistas, periódicos, folletos, control remoto y todo aquel adorno o aditamento que pueda ser tocado en la sala de espera. Se retirarán toallas del cuarto de baño y se pondrán toallas desechables.

- Protocolo de desinfección y esterilización. El virus es fácilmente eliminado con los procesos normales de limpieza, desinfección y esterilización siguiendo el de la clínica. Resulta conveniente tener preparado en paquetes el instrumental que se prevea va a ser empleado por sesión de trabajo.

- Vestimenta. El personal debe protegerse empleando sobre el uniforme bata tipo quirúrgica u overol, cubrebocas, careta y gorro por turno. Si hubiera contaminación de fluidos o sangre el cambio debe ser inmediato. Los guantes deberán ser cambiados entre un paciente y otro. Deberá evitar tocarse la cara. El cabello deberá recogerse y aretes, anillos, pulseras y relojes retirados. Los varones deberán rasurarse o proteger completamente la barba.

- El uniforme debe vestirse hasta llegar a las instalaciones de trabajo. Ni profesionales, asistentes o auxiliares deben llegar a la oficina dental portándolo como ropa de calle. De otra manera estarán introduciendo al ambiente clínico vestimenta contaminada (fómites) que atentan a los esfuerzos y gastos para establecer.

Al final de la jornada el uniforme es cambiado por ropa de calle dentro de las instalaciones de trabajo. La vestimenta personal puede ser rociada con productos indicados para este propósito. El uniforme debe ser lavado diariamente.

Durante el tratamiento de los pacientes el personal deberá portar sobre el uniforme bata de manga larga 
que no deje superficies de piel expuesta, las partes laterales de la cara deben ser protegidas por el cubrebocas, guantes, lentes, gorro y careta. Se debe evitar el contacto de saliva o sangre con piel, ojos, nariz o boca.

- Sana distancia. Debe ser operada entre el personal permanentemente, incluido el personal administrativo y de laboratorio (distancia de 1.5-2 metros entre cada persona).

- Visitas personales y acompañantes. No están permitidas las visitas personales. Es preferible que sólo llegue la persona que va a recibir atención. Los acompañantes no deben esperar dentro de las instalaciones clínicas. Se podrá contactar con ellos telefónicamente al final de la atención del paciente citado. Excepciones serán hechas con menores de edad y personas discapacitadas que requieran asistencia adicional.

- Inventarios. Es importante que al reiniciar actividades la clínica cuente con un inventario y reserva de insumos de protección (guantes, cubrebocas, batas desechables, caretas de protección, entre otros) suficiente para evitar rezagos en el desempeño.

\section{Personal de la clínica}

Entre otros aspectos previos a la apertura de la clínica se debe considerar revisar diariamente el estado de salud del personal que se reintegra a laborar, así como la capacitación constante y la práctica o simulacro de la ejecución de las políticas dictadas por la clínica sobre Control de Infecciones y Bioseguridad, debiendo considerar lo siguiente:

- Información y educación. El equipo de trabajo debe ser instruido con información científica sobre el SARS-CoV-2 y la infección COVID-19. Deberá recibir capacitación sobre las modificaciones al Protocolo de Control de Infecciones, cuya observancia será obligatoria e inevitable. Es importante recordarles que deben evitar recibir y difundir información no confiable o negativa que altere su estado de ánimo y les produzca ansiedad o depresión. Es importante estar al pendiente del bienestar emocional del equipo de trabajo y reforzar en ellos actitudes positivas. En caso necesario, buscar ayuda profesional sobre estos aspectos psicológicos. Igualmente, solicitar al personal que eviten hacer a los pacientes comentarios negativos sobre la epidemia.

- Selección de personal. El personal joven y sano, o aquéllos que ya sufrieron COVID-19 y se recuperaron, dejando de ser infecciosos, son los que preferente- mente darán atención directa a los pacientes; los primeros por tener mayores posibilidades de contar con un sistema inmunológico competente y los segundos por tener altos niveles en sangre de anticuerpos y células sensibilizadas que los protegen. Personas mayores de 60 años, aquéllos que sufren obesidad, diabetes o hipertensión, aquéllos bajo tratamiento con inmunosupresores, así como mujeres embarazadas, deberán quedar en lo posible lejos del contacto directo con pacientes.

- Vacunación. El personal de la clínica deberá contar con los esquemas de vacunación completos contra hepatitis B, tétanos y especialmente contra influenza estacional.

- Previsiones. Todo miembro del equipo de trabajo que manifieste fiebre, tos, dolor de garganta, dificultad para respirar y deterioro del estado físico deberá reportarse enfermo y buscar ayuda médica para descartar o confirmar COVID-19. En todos los estados de la República Mexicana existe una oficina, un sistema de respuesta rápida ante pacientes sospechosos y enfermos. El personal debe conocer el teléfono de contacto para acercarse al centro dedicado al diagnóstico y manejo de pacientes infectados. El afectado o sospechoso no deberá presentarse a la clínica hasta que se descarte la infección. Todo lo señalado en este párrafo es muy importante porque una persona con sintomatología que trabaje con pacientes pone en riesgo de cuarentena a todo el centro de trabajo.

\section{Recepción de pacientes}

Concertando la cita

El proceso de recepción de pacientes inicia desde la llamada telefónica en la que la persona solicita atención, o bien en la llamada del personal de recepción para recordarle al paciente su cita de control o para retomar nuevamente el tratamiento que fue interrumpido por la epidemia.

Durante la llamada telefónica, el mensaje o correo electrónico empleados para citar a los pacientes, se explicará que se ha elevado el nivel del Protocolo de Control de Infecciones de la clínica, en beneficio de la seguridad de ellos mismos. Cordialmente se les instará a apegarse al mismo. Ello significa que deberán acatar ciertas políticas como son:

a) Portar cubrebocas al llegar al recinto y al retirarse.

b) Responder y firmar un cuestionario que permita identificar el riesgo que puede representar el re- 
cibir un paciente con SARS-CoV-2 sintomático o asintomático, para determinar su atención en la clínica o su referencia al lugar especializado para tratamiento de pacientes con COVID-19.

c) Emplear el tapete sanitario y usar gel antibacterial al llegar a las instalaciones.

d) Para evitar aglomeraciones y poder cumplir con la sana distancia, preferentemente acudir solos o si son menores de edad o tienen alguna discapacidad, que asistan con sólo un acompañante.

e) Puede solicitárseles que al llegar al consultorio informen telefónicamente su arribo para, dado el caso de que no hubiera lugar en la sala de espera, pedirles que aguarden en el automóvil o en la cercanía, indicándoles que se les llamará cuando les toque su turno o haya espacio.

f) Deberán poner bajo resguardo el teléfono celular.

g) Puntualidad.

El personal de recepción debe ser cuidadoso en el manejo de la agenda para evitar aglomeración de pacientes en la clínica. Si es necesario, deberá espaciar las citas, para tener el tiempo suficiente de sanitizar los operatorios entre paciente y paciente, ya que este procedimiento puede requerir a veces hasta de 15-20 minutos, lo cual debe ser considerado.

Es recomendable que el paciente pague el tratamiento con tarjeta de crédito o débito, con transferencia bancaria o cheque y se evite en lo posible el uso de efectivo.

Recibiendo al paciente

Las siguientes son una serie de medidas que deben seguirse cuando ingrese una persona a la clínica:

- Medidas de higiene universales. El equipo de trabajo debe considerar a todos los pacientes, acompañantes, proveedores y a cualquier persona que ingrese a la clínica como potencialmente infecciosos, por lo que debe evitarse el saludo de mano, abrazos o besos.

- Disciplina. A todos los pacientes se les informará que se ha elevado el nivel del Protocolo de Control de Infecciones de la clínica, y que todos deberán apegarse a éste. Al llegar a la clínica, a cualquier persona se le invitará a pisar el tapete humedecido en hipoclorito de sodio (preparado con $30 \mathrm{~mL}$ de cloro en $970 \mathrm{~mL}$ de agua) y secar los zapatos en el paño o jerga dispuestos para ello. Se les pedirá usar gel hidroalcohólico antibacteriano, frotando las manos y entre los dedos durante 20 segundos y se les tomará la temperatura. No podrán ser atendidos pacientes con fiebre y deberán ser remitidos con el médico.

- Interrogatorio. A todos los pacientes y acompañantes se les pedirá contestar un cuestionario con las siguientes preguntas.

En los últimos 15 días:

A. ¿Ha tenido fiebre?

B. ¿Ha tenido malestar general, dolor muscular o deterioro del estado físico?

C. ¿Ha sufrido estornudos o tos?

D. ¿Ha sufrido diarrea o trastornos digestivos?

E. ¿Ha tenido pérdida del olfato o del gusto?

F. ¿Ha tenido dificultad para respirar?

G. ¿Ha estado en contacto con una persona positiva a COVID-19?

H. ¿Ha sufrido COVID-19?

Si alguna de las respuestas del listado de la A a la G fuera positiva LA CITA DEBERÁ POSPONERSE y referir al paciente a diagnóstico diferencial y eventual atención médica. Si la respuesta del ítem $\mathbf{H}$ (¿Ha sufrido COVID-19?) resultara positiva, la conducta a seguir será esclarecer si el paciente ya no es contagioso.

La prueba de laboratorio PCR (siglas en inglés de «reacción en cadena de la polimerasa»), permite detectar fragmentos del material genético de un patógeno o microorganismo, en este caso del COVID-19 (Tabla 1).

Las pruebas denominadas «RÁPIDAS», de muestras SANGUÍNEAS no están indicadas para determinar si el paciente es CONTAGIOSO, sólo indican, en caso de ser positivas, que el individuo ha estado en contacto con el virus a través de la presencia de anticuerpos.

En cambio, una prueba RÁPIDA POSITIVA DE EXUDADO NASOFARÍNGEO sí puede delatar la presencia viral, y consecuentemente la posibilidad contagiosa (Tabla 2).

Ante respuesta positiva a las otras preguntas, en una persona que tenga una urgencia como dolor, proceso infeccioso, traumatismo, fractura, entre otros problemas que ameriten tratamiento, deberá remitirse al paciente al hospital designado para la atención de pacientes con COVID-19, o sospechosos de padecerlo. Si la recepcionista tiene dificultad para interpretar las respuestas, deberá consultar con el odontólogo en jefe de la clínica para decidir el riesgo de infección cruzada que pueda representar el atender al solicitante. 
Tabla 1: PCR* prueba para COVID-19.

\begin{tabular}{lll} 
Indicaciones & Resultados & Conducta \\
\hline 1. Sospechoso & Negativo & Ofrecer atención odontológica \\
& Positivo & Esperar a que el individuo se transforme en negativo. Vigilancia médica requerida \\
2. Historia de COVID-19 & Negativo & Ofrecer atención odontológica \\
& Positivo & Esperar a que el individuo se transforme en negativo. Vigilancia médica requerida \\
\hline
\end{tabular}

* PCR, prueba que detecta con alta sensibilidad y especificidad la presencia del virus a través de fracciones de su ARN.

PCR positiva $=$ presencia viral y posibilidad de transmisibilidad.

PCR negativa = ausencia viral. Individuo no contagioso. Puede o no presentar anticuerpos elevados.

PCR = reacción en cadena de la polimerasa; ARN = ácido ribonucleico.

Es importante seguir esta política, porque de resultar el paciente positivo se corre el riesgo de que las autoridades sanitarias declaren a la clínica y a su personal en cuarentena.

- Precauciones en el área de recepción. El personal de esta área deberá lavarse las manos y cara cada hora o antes si fuese necesario, con jabón antibacterial. Es recomendable el uso de guantes para manejo de efectivo, y privilegiar el pago de honorarios con tarjeta de crédito o débito, cheque o transferencia bancaria.

- Vestimenta en general. El personal de recepción deberá usar cubrebocas, gorro, caretas (en caso de no tener una barrera de cristal o acrílico en el mostrador) y batas desechables de manga larga. El personal administrativo hará uso de batas desechables y cubrebocas, y el personal encargado de la limpieza portará batas desechables, cubrebocas, gorro y guantes de nitrilo.

\section{Durante el tratamiento}

- Preparación. El área operatoria debió haber sido preparada siguiendo el protocolo de control de infecciones de la clínica, lo cual incluye la limpieza y desinfección de pisos y superficies de trabajo, la colocación de cubiertas y barreras de protección en mesas de trabajo, manijas, botones, descansabrazos, piezas de mano, lámparas para resinas, cámaras intraorales, escáneres, mangueras, etcétera.

- Material e instrumental. Las charolas con el instrumental esterilizado, los elementos desechables como eyector, y material a emplear deben prepararse con anticipación, así como las bolsas para almacenar campos y material desechable que ya fue empleado.
Mantener bajo protección el material que no va a ser utilizado.

- Vigencia. Deberá usarse un par de guantes y cubrebocas por paciente y limpiar con jabón antibacterial la careta y lentes de protección al término de cada cita. De dañarse el cubrebocas, batas o guantes durante el procedimiento operatorio será necesario retirarlos y emplear nuevos.

- Actos preliminares inmediatos a la entrada del paciente. Previo a la entrada del paciente al operatorio, el odontólogo y su personal deberán lavarse manos y antebrazos y portar uniforme y vestimenta protectora adicional.

- Acomodo del paciente en el sillón dental. Al introducir al paciente al operatorio se le pedirá nuevamente usar gel hidroalcohólico antibacterial o le será rociado material antiséptico en manos y antebrazos. Sus pertenencias deben haber sido almacenadas en lugares indicados, o provista por el área de recepción de una toalla desechable impregnada con antiséptico para que manipule las correas de bolso o mochila.

- Preparación de cara y boca. Dado el hecho de que el virus SARS-CoV-2 es susceptible a la peroxidación es recomendable que la asistente ofrezca al paciente una torunda o almohadilla de algodón empapada en una solución de peróxido de hidrógeno al 1.5\%, para que la persona se limpie la cara, haciéndolo del centro a la periferia. Posteriormente, se le dará un enjuague de Microdacyn 60 bucofaríngeo (ácido hipocloroso, cloro oxígeno, solución de superoxidación), o de yodopovidona al $0.2 \%$ o una solución de peróxido de hidrógeno al $1.5 \%$ y se le pedirá que lo mantenga en la boca durante un minuto.

- Control de aerosoles. Ya que el virus se transmite a través de gotas de saliva, se debe evitar la producción 
de aerosoles provenientes de la boca. Por ello debe privilegiarse la instrumentación manual y el uso de aspiración de alta potencia. Si se cuenta con ellas se pueden utilizar ambas simultáneamente, la aspiración estándar junto con aquella quirúrgica. Evitar, indiscriminadamente, el uso de la pieza de alta velocidad, escariadores de ultrasonido o la jeringa triple. En aquellos procedimientos que sea posible colocarlo es indispensable emplear un dique de hule para limitar la dispersión de las gotas de agua y saliva. Es importante agendar para el final de la jornada a los pacientes en quienes se vayan a generar aerosoles, y cubrir con anteojos protectores los ojos del paciente.

- Implementos. El empleo de piezas de alta velocidad de flujo antirretractor y el empleo de eyectores de alta potencia impiden el flujo de regreso y limita la contaminación cruzada, por lo que deberán emplearse.

- Trabajo eficiente. La técnica de trabajo a cuatro manos facilita la rapidez de los procedimientos y hace eficiente el tiempo, además de mejorar el control de la diseminación de las gotas que se producen, por lo que debe llevarse a cabo en todos los procedimientos.

- Radiografías extraorales. Para los procedimientos de diagnóstico debe favorecerse el uso de técnicas extraorales de imagen, como la radiografía panorámica o la tomografía (Cone Beam CT), en lugar de emplear procedimientos intraorales como las imágenes periapicales.

- Suturas. En la realización de procedimientos quirúrgicos es preferible hacer uso de suturas absorbibles que no requieran el retiro de las mismas y así evitar citas que pudieran no ser necesarias.

- Sistema hidráulico. Aun cuando no hay soporte científico a la fecha que demuestre su eficacia contra el SARS-CoV-2, puede recomendarse el uso de hipoclorito de sodio para limpiar y purgar instrumentos como pieza de mano, jeringa triple y eyectores.

\section{Al terminar la consulta}

- Fin de la cita. Una vez terminados los procedimientos odontológicos y el paciente haber sido despedido, el operador y su personal deberán lavarse manos y cara. Deberá limpiarse con guantes las superficies que hayan sido tocadas y se empleará un bactericida en aerosol para sanitizar el espacio del operatorio empleado.

- Desecho de la indumentaria de trabajo. Deberán retirarse guantes, cubrebocas, batas, todos los campos y material como gasas, algodón, carpules y colocarse en los botes de desechos contaminados. Éstos deberán tener tapa y pedal para abrirse con el pie. Lo mismo aplica para agujas, bisturíes y material quirúrgico

\section{Tabla 2: Pruebas rápidas para COVID-19.}
Tipo de prueba
Resultados
Conducta

Exudado nasofaríngeo

Inmunocromatografía* en papel, donde están Negativo

adheridos anticuerpos $(\mathrm{Ab})$ contra el virus

$$
\begin{array}{ll}
\mathrm{Ac}+\text { virus }(\mathrm{Px})=\text { positivo } & \text { Positivo } \\
\mathrm{Ac}+\text { no virus }=\text { negativo } &
\end{array}
$$

Muestra sanguínea

Inmunocromatografía* en papel, donde están Negativo adheridas proteínas del virus

$$
\begin{aligned}
& \text { Virus }+\mathrm{Ac}(\mathrm{Px})=\text { positiva } \quad \text { Positivo } \\
& \text { Virus + no Ac = negativa }
\end{aligned}
$$

No hay presencia viral al momento de la toma

Puede ofrecerse atención odontológica

En cada futura cita debe ser repetido cuestionario con las preguntas de la $\mathrm{A}$ a la $\mathrm{H}$

Presencia viral. Posibilidad de contagio

Canalizar al individuo a atención médica

Puede ofrecerse atención odontológica

En cada futura cita debe ser repetido cuestionario con las preguntas de la $\mathrm{A}$ a la $\mathrm{H}$

Presencia de anticuerpos. Enfermedad presente o pasada. No concluyente para ofrecer servicios dentales. Solicitar prueba de exudado nasofaríngeo o PCR

* Prueba que por medio de la aparición de bandas coloreadas muestra los resultados.

Ac = anticuerpo; $\mathrm{Px}=$ paciente 0 probando. 
desechable. Debe solicitarse a la compañía que se encarga de eliminar el material contaminado que aumente la frecuencia para su retiro de la clínica.

- Acciones complementarias. Airear el operatorio durante cinco a 10 minutos evitando corrientes de aire. Limpiar con jabón antibacterial lentes y careta (el SARS-CoV-2 puede ser eliminado sin problemas con los procedimientos habituales de esterilización del instrumental). Desinfectar superficies y colocar nuevos campos de protección del equipo. Esta operación puede llevar entre 15 y 20 minutos.

- Personal de laboratorio. En el área de laboratorio el personal también deberá portar batas de manga larga, guantes, lentes y cubrebocas. En esa área se seguirá el protocolo correspondiente a la desinfección de impresiones y vaciado de modelos, empleando guantes de nitrilo.

- Manipulación del material y objetos del laboratorio. Las impresiones deberán ser limpiadas y enjuagadas en agua, desinfectadas y vueltas a enjuagar para ser secadas e introducidas en una bolsa de plástico para su envío al laboratorio externo. El SARS-CoV-2 puede ser resistente a la clorhexidina por lo que se recomienda:

- Si la impresión se tomó con alginato, desinfectarla con hipoclorito de sodio al $1 \%$ para después colocarla en una bolsa sellada por 10 minutos antes de enjuagarla.

- Si el material de impresión es un elastómero como las siliconas o el poliéster, se introducirá en la solución de hipoclorito de sodio al 1\% durante 15-20 minutos para su enjuague posterior.

- Para las prótesis de acrílico se empleará la misma solución y se deberá dejar inmersa en esa sustancia durante 10 minutos, enjuagándola posteriormente.

- Las prótesis de metal-cerámica o esqueletos de metal se pueden dejar inmersas en alcohol al 70\% durante cinco minutos.

- Para el envío de modelos, aditamentos y trabajo para el laboratorio externo, éstos deberán empacarse y manejarse con guantes.

- La solución de hipoclorito de sodio al 1\% pierde eficacia a las 24 horas, por lo que debe prepararse diariamente.

- Mensajería. El mensajero recibirá con guantes los documentos o las bolsas con los productos que deba despachar, así como al entregarlos o recibir material o documentación. El mensajero deberá evitar el contacto corporal con las personas donde entrega o recibe material, documentos o productos. Deberá llevar con él gel antibacterial y emplearlo al entrar y salir de cualquier recinto que visite.

\section{Cuando el equipo de trabajo abandona las instalaciones}

El Protocolo de Control de Infecciones en esta pandemia de COVID-19 no concluye al salir del trabajo, se extiende hasta la casa habitación del personal para evitar una infección cruzada que afecte a la familia. Por ello:

- Fin de la jornada diaria. Al término de la jornada laboral el personal deberá retirarse el uniforme y colocarlo en una bolsa de plástico, lavar cara, brazos y antebrazos y vestir ropa de calle.

- Deberá usar cubrebocas y guantes en el transporte público.

- Al llegar a casa deberá quitarse los zapatos y la ropa de calle y separarla. Es preferible dejar los zapatos afuera o en la zona de la cochera. Debe bañarse. Lavar uniforme y ropa de calle inmediatamente y separada del resto de la ropa de la familia. Si la ropa lo resiste, el lavado debe hacerse preferentemente a $60^{\circ}$ de temperatura.

- Desinfectar teléfono celular, bolsa, portafolios y todo aquello que haya sido trasladado del exterior hacia la casa.

- En el traslado casa-clínica, clínica-casa el personal deberá portar ropa de calle y una credencial u oficio que los acredite como trabajador de servicios de salud. Prohibido portar uniforme, filipina o bata.

El Protocolo de Control de Infecciones presentado se basa en las recomendaciones hechas por las agrupaciones gremiales y organizaciones sanitarias mundiales. ${ }^{5-12}$ No es rígido. Conforme se vayan presentando los descubrimientos y evidencias científicas sobre el tema puede sufrir modificaciones, por lo que el odontólogo debe estar al pendiente de los cambios que se vayan suscitando, debiendo hacer las adaptaciones pertinentes al mismo.

Lo cierto es que aunque el supuesto que se desarrolle en breve una vacuna eficaz, la profesión odontológica ya no es la misma y los cambios, incrementos y adecuaciones al Control de Infecciones y Bioseguridad, que en épocas pasadas se empleaba, serán todos en beneficio de la calidad de la atención y seguridad de todas las personas.

\section{CONCLUSIONES}

El regreso a la NUEVA NORMALIDAD obliga a elevar el nivel de Control de Infecciones y Bioseguridad en la consulta odontológica, de tal forma que se brinde seguridad no sólo a los pacientes, sino también al personal y equipo 
de trabajo, a proveedores y colaboradores externos y a las familias de todos ellos.

Es probable que este incremento en el nivel de bioseguridad se integre de manera irreversible al quehacer odontológico, lo cual será de enorme beneficio para la protección de las personas durante ésta y, aunque no deseables, futuras epidemias.

\section{BIBLIOGRAFÍA}

1. Peng X, Xu X, Li Y, Cheng L, Zhou X, Ren B. Transmission routes of 2019-nCoV and controls in dental practice. Int J Oral Sci. 2020. 12 (1): 9. doi: 10.1038/s41368-020-0075-9.

2. Huang Ch, Wang Y, Li X, Ren L, Zhao J, Hu Y et al. Clinical features of patients infected with 2019 novel coronavirus in Wuhan, China. Lancet. 2020; 395: 497-506.

3. To KK, Tsang OT, Yip CC, Chan K, Wu T, Chan JM et al. Consistent detection of 2019 novel coronavirus in saliva [published online ahead of print, 2020 Feb 12]. Clin Infect Dis. 2020; ciaa149. doi: 10.1093/cid/ciaa149.

4. Ki M; Task Force for 2019-nCoV. Epidemiologic characteristics of early cases with 2019 novel coronavirus (2019-nCoV) disease in Korea. Epidemiol Health. 2020; 42: e2020007. doi: 10.4178/epih. e2020007.

5. World Health Organization. Surveillance strategies for COVID-19 human infection: Interim Guidance 10 May 2020. Geneva: World Health Organization; 2020. Available in: https://www.who.int/ publications-detail/surveillance-strategies-for-covid-19-humaninfection [Accessed 2 June 2020]

6. CDC Interim Infection Prevention and Control Guidance for Dental Settings during the COVID-19 Response. Available in: https://www. cdc.gov/coronavirus/2019-ncov/hcp/dental-settings.html

7. FDI. FDI Council statement on dentistry and oral health during the COVID-19 pandemic. Available in: https://www.fdiworlddental.org/ fdi-covid-19-resource-library [Accessed 2 june 2020]

8. Secretaría de Salud. Centro Nacional de Programas Preventivos y Control de Enfermedades (CENAPRECE). Programa de Salud Bucal Nacional. Recomendaciones para la práctica Odontológica. 2020.

9. American Dental Association. Council on Dental Practice. ADA Interim Guidance for minimizing Risk for COVID-19 transmission. 2020. Available in: https:/www.ada.org.au/Covid-19-Portal/DentalProfessionals
10. American Dental Association. Council on Dental Practice. Return to work interim guidance toolkit. Available in: https://success.ada. org/ /media/CPS/Files/OpenFiles/ADA_Return_to_Work_Toolkit. pdf

11. Consejo Dentistas. Organización Colegial de Dentistas de España. Plan estratégico de acción para el periodo posterior a la crisis creada por el COVID-19. Versión 13 de abril de 2020.

12. Consejo Dentistas. Organización Colegial de Dentistas de España. Plan estratégico de acción para el periodo de desescalada COVID-19. Versión $1^{\circ}$ de mayo de 2020.

13. Castellanos J, Díaz Guzmán LM. El Miedo es contagioso. Menoscabo por una pandemia. Rev ADM. 2020; 77 (3). [En prensa]

14. Castellanos JL, Hernández A. Tiempos difíciles, tiempos de oportunidad. Rev ADM. 2002; 59 (4): 144-153.

15. Acosta E. SARS Coronavirus 2. Guía para el control de infecciones en el consultorio odontológico. Available in: https://amein.org.mx/ downloads_nor/EAG SARS-CoV-2 y COVID-19 mayo 21.pdf [Mayo 21, 2020]

16. Chu DK, Akl EA, Duda $S$, Solo K, Yaacoub $S$, Schünemann HJ. Physical distancing, face masks, and eye protection to prevent person-to-person transmission of SARS-CoV-2 and COVID-19: a systematic review and meta-analysis [published online ahead of print, 2020 Jun 1]. Lancet. 2020; S0140-6736(20)31142-9. doi: 10.1016/S0140-6736(20)31142-9.

17. Galíndez AJ. Procedimientos de limpieza y desinfección de espacios clínicos. Procedimientos de control y protección de personal sanitario y pacientes. Adaptados a la actividad en centros sanitarios odontológicos según normativa con relación a la Pandemia de COVID-19. Odontólogos de hoy. 2020; 19 (42): 44-48.

18. Robles D, Rodríguez CE. COVID-19 y la consulta dental: información y consejos. Gaceta Dental. Mayo 2020.

19. Acosta Gío E. Prevención y control de infecciones en el consultorio dental. En: Prótesis parcial removible. Ciudad de México: Editorial Trillas; 2016. ISBN 9978-607-17-2692-6.

20. Thomé G, Bernardes S, Guandalini S. Manual de buenas prácticas en bioseguridad para ambientes odontológicos. México: Neodent, Straumann; 2020. pp. 42. Disponible en: https:// asociacionmexicanadeperiodontologia.com/Imagenes/ManualBioseguridad-full-ESP.pdf

\section{Correspondencia:}

Dra. Laura María Díaz Guzmán

E-mail:diazlaura@hotmail.com 